\title{
Travel purpose and expenditure patterns in city tourism: evidence from the Amsterdam Metropolitan Area
}

\author{
Ruben van Loon $^{1} \cdot$ Jan Rouwendal ${ }^{1}$ (iD
}

Received: 18 July 2016/ Accepted: 18 January 2017/Published online: 25 February 2017

(C) The Author(s) 2017. This article is published with open access at Springerlink.com

\begin{abstract}
This study examines the expenditure patterns of urban tourists with different trip purposes including visiting cultural heritage. Expenditure categories include museums and theatres. We use a two-step approach, in which we first analyse the total daily amount of expenditure and then the budget shares of various categories. We make use of survey data collected for the Amsterdam Metropolitan Area, a large Western European city known for its rich cultural heritage and the semi-legalized use of cannabis. The econometric analysis shows that trip purposes are associated with substantial differences in total daily expenditure as well as on budget shares. However, the results also show that the activities undertaken by tourists are not limited to their (initial) trip purposes.
\end{abstract}

Keywords Trip purpose - Tourism expenditure $\cdot$ Expenditure patterns $\cdot$ Cultural heritage $\cdot$ Cannabis

JEL Classification C31 $\cdot$ D12 $\cdot$ L83

\section{Introduction}

In most West European capitals and other large cities, tourism is of substantial importance for the local economy. Tourists visiting a particular city often differ widely in their travel motives. History, museums, the design of the city and its

Ruben van Loon

R.R.van.loon@vu.nl

Jan Rouwendal

J.Rouwendal@vu.nl

1 Department of Spatial Economics, VU University Amsterdam, De Boelelaan 1105,

1081 HV Amsterdam, The Netherlands 
historical buildings, theatres, music halls, the cultural atmosphere may all contribute to its attraction for various groups of tourists. City marketers emphasize the various aspects to attract different groups of visitors. It seems likely that the travel motives of these visitors, which are related to the aspects of the city that attract them, are also related to their activities and expenditure patterns and, through this, to their impact on the local economy. However, little seems to be known about such differences and it is the purpose of this paper to shed more light on this issue by studying the expenditure pattern of tourists with different travel motives, while controlling for other potentially important determinants of expenditure like country of origin.

The data we analyse refer to the Amsterdam Metropolitan Area in the Netherlands. ${ }^{1}$ Amsterdam is an important attractor of tourists in Western Europe and the major tourist city of the Netherlands. People from all over the world visit the city. Like many other Western European cities, Amsterdam is an old city, founded in the Middle Ages, with a wide range of cultural heritage. Van der Ark and Richards (2006) state that culture has become a major driving force of the urban tourism system. The canals and the related cultural heritage of the seventeenth century 'Golden Age' of the city are probably the 'trademark' of the city, and a large part of the ancient centre is on the UNESCO World Heritage list. However, this is certainly not the only amenity that Amsterdam has to offer. The Amsterdam museums (the Rijksmuseum and the Van Gogh Museum are probably the best-known examples) also have international reputations. Moreover, and partly related to this, Amsterdam is a popular location for conferences and exhibitions. Amsterdam is also widely known for the Dutch governments' tolerance for the use and sale of cannabis. In the Netherlands, its use and selling are quasi-legalized which has given Amsterdam in particular a reputation as a 'cannabis Valhalla' among foreigners and consequently tourists. The focus on Amsterdam thus offers the possibility to investigate the expenditures of tourists who come with widely different travel motives ranging from visiting Amsterdam's cultural heritage to experiencing the quasi-legalized cannabis scene.

This paper is structured as follows. Section 2 briefly reviews existing empirical studies on tourism expenditure analysis at the micro-level. Section 3 describes the data we use and provides some descriptives. Section 4 elaborates briefly on the micro-econometric method used and reports estimation results for total daily expenditure and budgets shares of a number of categories. Section 5 concludes.

\section{Background/literature}

From the point of view of consumer economics, a tourism trip as a whole can be considered as a differentiated product. ${ }^{2}$ Even since Lancaster (1966) and Gorman $(1980)^{3}$ economists have shown an interest in the analysis of such markets by

\footnotetext{
1 From now on, 'Amsterdam' is used as an abbreviation for the Amsterdam Metropolitan Area.

2 Indeed, the distinction between consuming a standard differentiated product like a restaurant meal and a tourism trip is somewhat fluid, as some such trips have culinary experiences as their main travel purpose. See, for instance, Smith and Costello (2009).

3 This paper was actually written in 1956 and is one of the classic references for the analysis of differentiated products.
} 
regarding the product as a bundle of characteristics that are jointly consumed and together determine the utility derived from consuming one or more units of the commodity. Looking at tourism destination choice through this lens is illuminating. In city tourism, the characteristics of the destination, like the museums, cultural heritage, theatres, et cetera, determine its attractiveness. There is also a difference: unlike the characteristics of many differentiated products that usually all have to been consumed in predetermined packages, the tourist can choose to emphasize consumption of some-for instance by making long trips to all the major museums - and avoid others - for instance by abstaining from the use of cannabis when visiting Amsterdam. The various characteristics of the destination can thus be given more or less emphasis by the tourist, who is therefore able-at least to some extend-to construct her own variety of the product. What is chosen is clearly related to his or her preferences or travel motive, and it usually has implications for the expenditure associated with the trip. The focus of the present paper is on the implications the various travel motives have on expenditure. Visitors of Amsterdam that are mainly interested in its museums will spend more on tickets, but may also tend to choose luxury hotels and cosy restaurants, whereas those that mainly come for cannabis consumption may spend relatively little on other consumption categories. In the analysis that follows, we investigate these questions by distinguishing two 'layers' of expenditure. We are interested in total trip expenditure, and in the way, it is divided over the various categories of consumption goods. Following established practice in consumer economics (see Deaton and Muellbauer 1980), we estimate equations for total trip expenditure and for the budget shares of relevant subcategories of consumption goods.

The analysis that follows can thus be interpreted as a study of how consumers with different tastes - which are reflected in their travel motives-compose their own version of the differentiated product 'a trip to Amsterdam'. Alternatively, it can be regarded as a more conventional analysis of consumer behaviour in which households are thought of as spending their total budget on a number of categories that are separable in their preferences, ${ }^{4}$ which means that the division of the budget spent on the category as a whole-the trip to Amsterdam in this case-over subcategories (accommodation, food, etc.) can be analysed independently of the expenditure on other categories (like consumption at home). This view also suggests that the absence of information on income (or education, which is often used as a proxy) does not matter for the budget share equations that we estimate in this paper, ${ }^{5}$ although for the purposes of explaining the total trip budget we would certainly have preferred to have information about the household's income ${ }^{6}$ or a good proxy of that income. Moreover, information on income would have provided relevant additional context to the analysis.

\footnotetext{
${ }^{4}$ See Deaton and Muellbauer (1980) for extensive discussion.

5 The reason is that conditioning on the total expenditure of the trip to Amsterdam is sufficient to control also for the impact of total expenditure or income.

6 In particular if incomes originating in different countries could be made comparable using a real effective exchange rate (REER).
} 
A large part of the existing tourism demand literature makes use of aggregate data such as total arrivals and total expenditures in a tourist destination (Crouch 1994, 1995; Lim 1997, 1999, 2006; Wang and Davidson 2010). Micro-economic studies are less common, but their annual number has been increasing since the year 2000 (Wang and Davidson 2010). The use of survey data, often collected by local and/or national tourism authorities, is very common in this branch of the literature, and this study is no exception. Wang and Davidson (2010) classify micro-economic tourism studies into three groups: analyses of optimal choice in tourism demand; analyses of factors that affect individual tourist expenditures on a given trip; and analyses aimed at modelling tourism prices. Our paper fits into the second group and thus focuses on individual expenditures on a given trip. The theoretical background of the equations we estimate is the conventional micro-economic theory that presumes optimizing behaviour, see, for instance, Deaton and Muellbauer (1980). With respect to the determinants of micro-level tourism expenditures, Wang et al. (2006) indicate that prior research often distinguishes trip-related characteristics from socio-demographic and psychographic variables.

Trip-related characteristics affect tourism expenditures heavily. For example, Thrane and Farstad (2011) find that length of stay and travel party size are important determinants of individual expenditures and observe that both have a nonlinear impact. They find a positive relationship between length of stay and tourism expenditure, but the marginal impact of an additional day decreases. They also find a convex relationship between the size of the travel party and tourism expenditure. Other trip characteristics like type of trip, business or pleasure, and trip purpose, are of interest (Thrane and Farstad 2011). Distance to the destination is another individual characteristic that is often included in tourism expenditure models (Nicolau and Mas 2005). Wang et al. (2006) and Wu et al. (2013) found that tourism expenditures are positively related to distance. Presumably, this is, at least partly, a selection effect: for those who have most to spend, travel costs to remote destinations are also less important. In economic tourism studies, personal income or household income is a widely used variable (Eymann and Ronning 1997). Research has found that in North West Europe tourists with high income levels are more likely to make a city trip than those with lower income levels (WTO 2005). Other frequently used socio-demographic characteristics are age, sex, marital status, and size of the place of residence (Eymann and Ronning 1997). Some studies distinguish first-time and repeat visitors. For instance, Opperman (1996) studies the travel expenditures of first-time versus repeat visitors to Rotorua, New Zealand, and Opperman (1997) describes the results of similar analyses for multiple countries. Although the spending patterns of both groups were generally found to be somewhat different, the results vary per country and no unambiguous indication was found that repeat visitors spend more, or stay longer.

For marketing purposes, market segmentation is often important and a number of studies have looked at tourist behaviour and expenditure from that perspective. For instance, Chung et al. (2004) analyse data about visitors of super deluxe hotels in Seoul to find meaningful market segments and Laesser and Crouch (2006) have a similar purpose in their analysis of holiday travellers to Australia. Cluster analysis, and factor and principal component analysis are popular techniques in this branch of 
the literature. In other cases, the main purpose is to distinguish the big and small spenders (Spotts and Mahoney 1991; Mok and Iverson 2000; Thrane 2002; Pouta et al. 2007; Allegre et al. 2011; Mehmetoglu 2007). Still other researchers have used trip expenditure, income and household characteristics to classify tourists into trip types (Sung et al. 2001). Wang and Davidson (2010) state in their paper that psychological and trip-related factors may greatly affect the level of expenditure and that research in this area would contribute to the literature on this topic. The present paper is an attempt to do so by focusing on the relationship between selfreported main travel motives and expenditure on a number of consumption categories, while controlling as best as we can for other determinants of expenditure, like the ones discussed above.

\section{Data}

\subsection{Data collection}

The data that are used in this study originate from the Amsterdam visitor surveys from 2006 to 2011 (AMSTERDAM MARKETING 2012). These data inform us about the main travel purpose(s) of the tourist, provide some background information including the country of origin, and have relatively detailed questions about the tourist's expenditure pattern. Questions asked were about activities for the whole trip, including those activities respondents were planning to undertake. The surveys took place between March and October. Perhaps the main shortcoming is that the survey does not provide information about income or education of the respondents.

It may be observed that street interviews are not necessarily the best way to collect detailed information about consumption expenditure of tourists. A clear disadvantage is that the tourist has to interrupt their activities to answer a relatively large number of detailed questions about their travel motives and expenses. There is a risk of selective non-response and of rapid and inaccurate responses to some of the questions posed. It must, however, be realized that such disadvantages also exist when respondents are approached via the internet or by mail although they are perhaps less substantial. ${ }^{7}$ Since these alternative ways of collecting data are harder to use for tourist expenditure, we feel that our data are at least reasonable as the basis of an investigation of tourist expenditure. It may also be noted that random measurement error tends to bias estimated coefficients towards 0 , which suggests that our estimated coefficients are underestimates of the associated effects of the explanatory variables.

In the year 2006, the current economic crisis had not yet started, while in 2011 it had been around for some years. For the years 2006 and 2011, respectively, 6184 and 10,199 tourists in Amsterdam and the Amsterdam Metropolitan Area were interviewed. The interviews took place at different locations, usually close to tourist accommodation, (shopping) streets, attractions, museums, transfer points and

\footnotetext{
7 See Fricker et al. (2015) for a recent review.
} 
convention centres. In total, about $65 \%$ of the interviewed tourists stayed for an overnight visit, and we limit our study to these observations. For the analysis in this paper, 9594 (3690 for the year 2006 and 5904 for the year 2011) observations of respondents who stayed overnight are used. Observations with missing or inconsistent information were dropped. We include a dummy variable to control for differences in spending patterns between the 2 years.

In Table 6 of the Appendix, the categorization of the travel purposes is explained. The respondents could mark multiple options for their travel purpose to visit Amsterdam; we checked this and grouped related purposes into single-purpose categories: cultural, cannabis, event/exhibition, mixed purposes and a rest category. ${ }^{8}$

\subsection{Descriptive statistics}

Table 1 shows that tourists who visit Amsterdam spend on average $€ 139.01$ per person per day. ${ }^{9}$ The median is lower, $€ 114.68$, and Fig. 1 shows that the distribution of the personal daily budgets is skewed. The budgets with the highest frequency are between 20 and 180 euros.

Table 1 shows that 34 and $30 \%$ of the average daily budget are spent on accommodation and food, respectively; expenditures on shopping are next with $15 \%$ on average; and museums take the fourth place with $10 \%$ on average. Expenditures on cannabis are on average at $3 \%$ of the daily budget, and respondents allocate on average almost $4 \%$ of their daily budget to clubbing (going to bars, cafés and clubs).

Tourists stay on average 4.52 days in Amsterdam, and the average travel party size is 3.18 people. The large maximum values for days of stay (100 days) and travel party size (399 people) are outliers in the data set. ${ }^{10}$ The average age of the respondents was 38.14 years and $51 \%$ of them were males. Of the respondents, $7 \%$ visited Amsterdam for business activities and $93 \%$ for a vacation.

The travel purposes are distributed as follows: $53 \%$ of the tourists indicated that they had come to Amsterdam to see the old city and the canals; $3 \%$ to visit a special event or exhibition; $3 \%$ for the use of cannabis; $10 \%$ of the tourists had mixed purposes; and $31 \%$ had another travel purpose. Note that the travel purpose does not completely determine actual behaviour. Although only $3 \%$ indicate cannabis as the main travel purpose, $30 \%$ of our respondents actually indicated that they had visited a cannabis shop, and no less than $76 \%$ indicated that they had visited a museum. This finding shows that many tourists coming to Amsterdam for one specific amenity also appreciate other characteristics of the city. The various attractors of tourists appear to be complements, rather than substitutes.

\footnotetext{
${ }^{8}$ Although Amsterdam's red light district is worldwide, perhaps the city's best-known characteristic, sex or visiting prostitutes, was not used as a possible travel motive in the survey. Nor was gay tourism identified as a separate category. It is possible that tourists with such (primary) travel purposes have indicated other (perhaps secondary) purposes. This may imply that the results for these other purposes are somewhat biased.

9 The daily personal budget excludes travel cost to Amsterdam.

${ }^{10}$ When we introduced cut-off values for these variables in the analyses, estimation results did not change, so we decided to include these outliers.
} 
Table 1 Descriptive statistics for the main study variables Source: AMSTERDAM MARKETING, Amsterdam visitor survey (2006 and 2011)

\begin{tabular}{|c|c|c|c|c|}
\hline Variable & Mean & $\mathrm{SD}$ & Min & $\operatorname{Max}$ \\
\hline Total & $€ 139.01$ & $€ 102.09$ & $€ 1.83$ & $€ 2.275$ \\
\hline Total (median) & $€ 114.68$ & & & \\
\hline Euro accommodation & $34.05 \%$ & $23.53 \%$ & $0.00 \%$ & $100.00 \%$ \\
\hline Euro food & $29.63 \%$ & $18.49 \%$ & $0.00 \%$ & $100.00 \%$ \\
\hline Euro parking and transport & $3.90 \%$ & $7.35 \%$ & $0.00 \%$ & $100 \%$ \\
\hline Euro museums & $9.70 \%$ & $11.40 \%$ & $0.00 \%$ & $100 \%$ \\
\hline Euro theatre & $0.71 \%$ & $4.16 \%$ & $0 \%$ & $79 \%$ \\
\hline Euro cannabis & $2.67 \%$ & $6.66 \%$ & $0 \%$ & $83 \%$ \\
\hline Euro shopping & $14.54 \%$ & $18.43 \%$ & $0 \%$ & $100 \%$ \\
\hline Euro clubbing & $3.73 \%$ & $8.52 \%$ & $0 \%$ & $100 \%$ \\
\hline Euro remaining & $0.91 \%$ & $4.59 \%$ & $0 \%$ & $100 \%$ \\
\hline Days of stay & 4.52 & 4.09 & 1 & 100 \\
\hline Travel party size & 3.18 & 9.66 & 0 & 399 \\
\hline Sex dummy $($ male $=1)$ & 0.51 & 0.50 & 0 & 1 \\
\hline Age & 38.14 & 15.47 & 16 & 99 \\
\hline Vacation dummy $($ vacation $=1)$ & 0.93 & 0.25 & 0 & 1 \\
\hline \multicolumn{5}{|l|}{ Travel purpose: } \\
\hline Mixed purposes & $10 \%$ & $30 \%$ & & \\
\hline Culture (old city and canals) & $53 \%$ & $50 \%$ & & \\
\hline Special event or exhibition & $3 \%$ & $18 \%$ & & \\
\hline Cannabis use & $3 \%$ & $18 \%$ & & \\
\hline Different purposes & $31 \%$ & $46 \%$ & & \\
\hline Actual cannabis shop visit & $30 \%$ & $46 \%$ & & \\
\hline Actual museum visit & $76 \%$ & $43 \%$ & & \\
\hline
\end{tabular}

$N=9594$ (years 2006 and 2011)

Table 2 shows the correlation between the indicated travel purpose and actual visits to a cannabis shop and a museum. It indicates that the correlation between the travel purpose cannabis and visiting a cannabis shop is relatively weak, as is the correlation between the travel purpose culture and visiting a museum. There is only a slightly negative correlation between the travel purposes cannabis and visiting a museum, and between the travel purposes culture and visiting a cannabis shop. Those visiting Amsterdam for mixed purposes are substantially less likely to visit either a museum or a cannabis shop (but especially the former!), which suggests that their actual travel purpose is not a mixture of culture and cannabis. Coming to Amsterdam for an event or exhibition is only slightly negatively correlated with visiting a cannabis shop and more clearly negatively related to visiting a museum. The correlation matrix also shows that actual museum visits and actual cannabis shop visits are almost uncorrelated, showing that those who visit a museum are as 


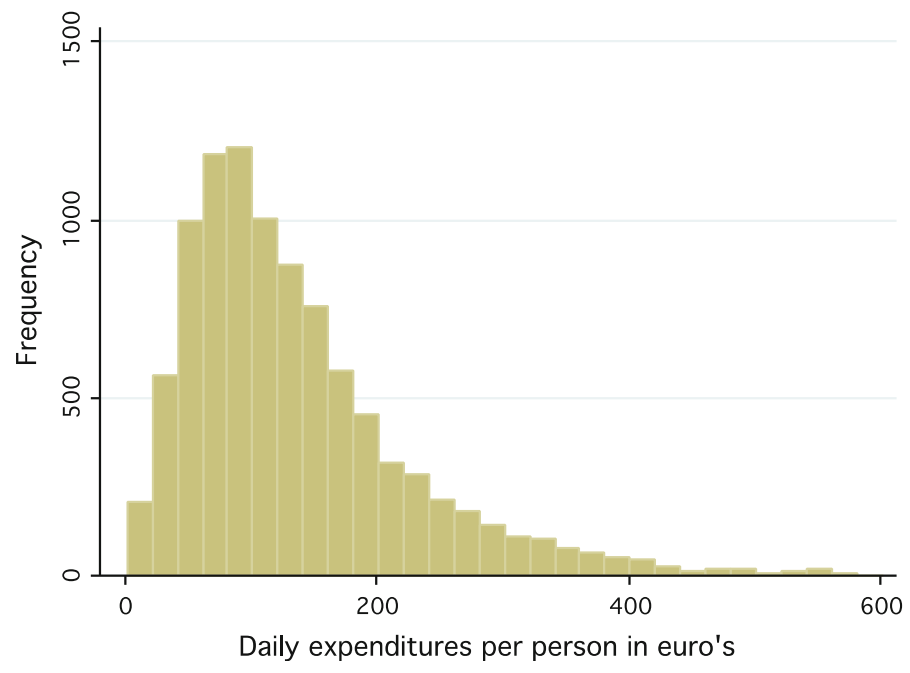

Fig. 1 Frequency distribution of expenditures per person per day

Table 2 Correlation matrix for trip purpose and undertaken activities

\begin{tabular}{llllllll}
\hline Dummy for: & $\begin{array}{l}\text { Mixed } \\
\text { purposes }\end{array}$ & $\begin{array}{l}\text { Purpose } \\
\text { culture }\end{array}$ & $\begin{array}{l}\text { Purpose } \\
\text { event or } \\
\text { exhibition }\end{array}$ & $\begin{array}{l}\text { Purpose } \\
\text { cannabis }\end{array}$ & $\begin{array}{l}\text { Different } \\
\text { purpose }\end{array}$ & $\begin{array}{l}\text { Actual } \\
\text { cannabis } \\
\text { shop visit }\end{array}$ & $\begin{array}{l}\text { Actual } \\
\text { museum } \\
\text { visit }\end{array}$ \\
\hline $\begin{array}{c}\text { Actual } \\
\text { cannabis } \\
\text { shop visit }\end{array}$ & -0.144 & -0.006 & -0.082 & 0.226 & 0.044 & 1.000 & 0.079 \\
$\begin{array}{c}\text { Actual } \\
\text { museum } \\
\text { visit }\end{array}$ & -0.344 & 0.288 & -0.135 & -0.096 & -0.002 & 0.079 & 1.000 \\
\hline
\end{tabular}

likely to also visit a cannabis shop as those who do not visit a museum, and vice versa.

In Table 3, we show the distributions of the respondents with different trip purposes who actually undertake the activities visiting a museum or a cannabis shop, or not. We see that, of the respondents with mixed trip purposes, most do not visit a museum (68\%) and do not visit a cannabis shop (90\%). Of the respondents with culture as travel purpose, $88 \%$ visit a museum and $30 \%$ visit a cannabis shop. Respondents coming to Amsterdam to visit an event are spread almost evenly with respect to museum visits, but a large percentage (91\%) of them do not visit a cannabis shop. If cannabis is the travel purpose, museum visits are also more evenly distributed: $54 \%$ visit a museum. It is remarkable that $13 \%$ of the respondents with a cannabis purpose do not visit a cannabis shop. It is noticeable that cannabis shop visits are not exclusively reported by respondents with a cannabis trip purpose. For instance, of the respondents with a trip purpose belonging to the rest category, $76 \%$ visit a museum and $30 \%$ visit a cannabis shop. 
Table 3 Actual undertaken activities by trip purpose
Table 4 Cannabis shop and museum visits crossed

\begin{tabular}{|c|c|c|c|c|c|}
\hline \multirow[t]{2}{*}{ Travel purpose } & \multicolumn{2}{|c|}{ Museum visit } & \multicolumn{2}{|c|}{ Cannabis shop visit } & \multirow[t]{2}{*}{ Total } \\
\hline & No & Yes & No & Yes & \\
\hline \multirow[t]{2}{*}{ Culture } & 612 & 4427 & 3524 & 1515 & 5039 \\
\hline & $12 \%$ & $88 \%$ & $70 \%$ & $30 \%$ & $53 \%$ \\
\hline \multirow[t]{2}{*}{ Event } & 170 & 136 & 277 & 29 & 306 \\
\hline & $56 \%$ & $44 \%$ & $91 \%$ & $9 \%$ & $3 \%$ \\
\hline \multirow[t]{2}{*}{ Cannabis } & 143 & 166 & 39 & 270 & 309 \\
\hline & $46 \%$ & $54 \%$ & $13 \%$ & $87 \%$ & $3 \%$ \\
\hline \multirow[t]{2}{*}{ Mixed purposes } & 638 & 294 & 837 & 95 & 932 \\
\hline & $68 \%$ & $32 \%$ & $90 \%$ & $10 \%$ & $10 \%$ \\
\hline \multirow[t]{2}{*}{ Other purposes } & 719 & 2289 & 2006 & 1002 & 3008 \\
\hline & $24 \%$ & $76 \%$ & $67 \%$ & $33 \%$ & $31 \%$ \\
\hline \multirow[t]{2}{*}{ Total } & 2282 & 7312 & 6683 & 2911 & 9594 \\
\hline & $24 \%$ & $76 \%$ & $70 \%$ & $30 \%$ & $100 \%$ \\
\hline
\end{tabular}

\begin{tabular}{llll}
\hline Actual cannabis shop visit & \multicolumn{2}{l}{ Actual museum visit } & Total \\
\cline { 2 - 3 } & 0 & 1 & \\
\hline 0 & $18.1 \%$ & $51.5 \%$ & $69.6 \%$ \\
1 & $5.7 \%$ & $24.7 \%$ & $31.4 \%$ \\
Total & $23.8 \%$ & $76.2 \%$ & $100 \%$ \\
\hline
\end{tabular}

In Table 4, the museum and cannabis shop visits of the respondents are crossed. The majority of respondents $(51.5 \%)$ only visit a museum, and $69.6 \%$ of the respondents do not visit a cannabis shop. And only $5.7 \%$ of the respondents visit only a cannabis shop and no museum. About a quarter $(24.7 \%)$ of the respondents visit both a museum and a cannabis shop. Of the total respondents, those indicating to come for cannabis are a small group, and - judged by their behaviour-many of them appear to have other travel motives as well.

In the regressions reported in the next section, we include 13 dummies for country of origin in our model. They refer to most of the European countries, some important non-European countries (USA, China, Russia) and an 'other-countries' dummy for the countries not especially distinguished with a dummy variable. The reference country is the Netherlands. Unfortunately, we have no information on the income of our respondents; neither do we have information on their education level.

\section{Method and results}

\subsection{Method}

To analyse the information on expenditure by tourist, we use a two-step approach, in which we first analyse the total daily amount of expenditure, and second the budget 
shares of various categories in this total. From the point of view of economic theory of consumer behaviour, this approach can be motivated by the assumption that goods consumed during a holiday are separable from other goods in the consumer's utility function. ${ }^{11}$ This means that we can analyse the expenditure pattern during the consumer's visit to Amsterdam conditional on the budget that is available for the trip without having to pay attention to the tourists' consumption behaviour in his or her home country. Our empirical specification of the budget share equations is consistent with the almost ideal demand system of Deaton and Muellbauer (1980). Since we do not have much information about prices (and our observations refer only to 2 years), we estimate no price coefficients, but only Engel curves. We estimate an equation for total daily expenditure per capita, and budget share equations for a number of expenditure categories: lodging, meals/restaurants, transport and parking, shopping, museums visits, theatre visits, cannabis, club/bar visits and other expenditures).

The (economic) importance of the tourism sector for Amsterdam, and other Western European capitals, motivates an interest in the effects of sociodemographic, travel-related and psychological variables on travel expenditures. And especially for policy makers in Amsterdam, our distinction between 'cannabis tourists' and 'cultural tourists' is potentially of interest. Wang et al. (2006) already pointed out in their survey that research on the attitudes towards and perceptions of destinations and their impacts on spending patterns is a worthwhile topic.

\subsection{Total daily expenditures}

Table 5 presents the results of the regression analyses. Column 1 shows the results of the OLS regression, with total euros spent per person per day as the dependent variable, and in columns 2-9 the share of the total daily amount spent per person (budget share), of each consecutive spending category, is used as the dependent variable. In the present subsection, we discuss the estimation results of the total daily expenditures.

The focus of interest is are four trip purpose dummies. We find widely differing coefficients, indicating substantial differences in spending. 'Other purposes' has been used as the reference category, and we find that respondents with mixed purposes spend on average more than $€ 30$ pppd less. ${ }^{12}$ Those coming to Amsterdam for a special event or an exhibition or for cannabis spend significantly more than this group. It is remarkable that tourists coming mainly for cannabis spend-after controlling for other variables_-almost as much per day as those coming for special events or exhibitions. The difference between the daily expenditures of those interested especially in culture, and the reference group is relatively small and not statistically significant. We thus find widely differing amounts spent pppd that are related to travel purposes, confirming Wang and Davidson's (2010) conjecture.

\footnotetext{
11 For an extensive discussion of separability and two-stage budgeting, see Deaton and Muellbauer (1980). We note that assuming separability is restrictive-its popularity notwithstanding-and that information about tourist income would have allowed us to test its validity.

12 This amounts to more than $20 \%$ of average daily expenditure.
} 


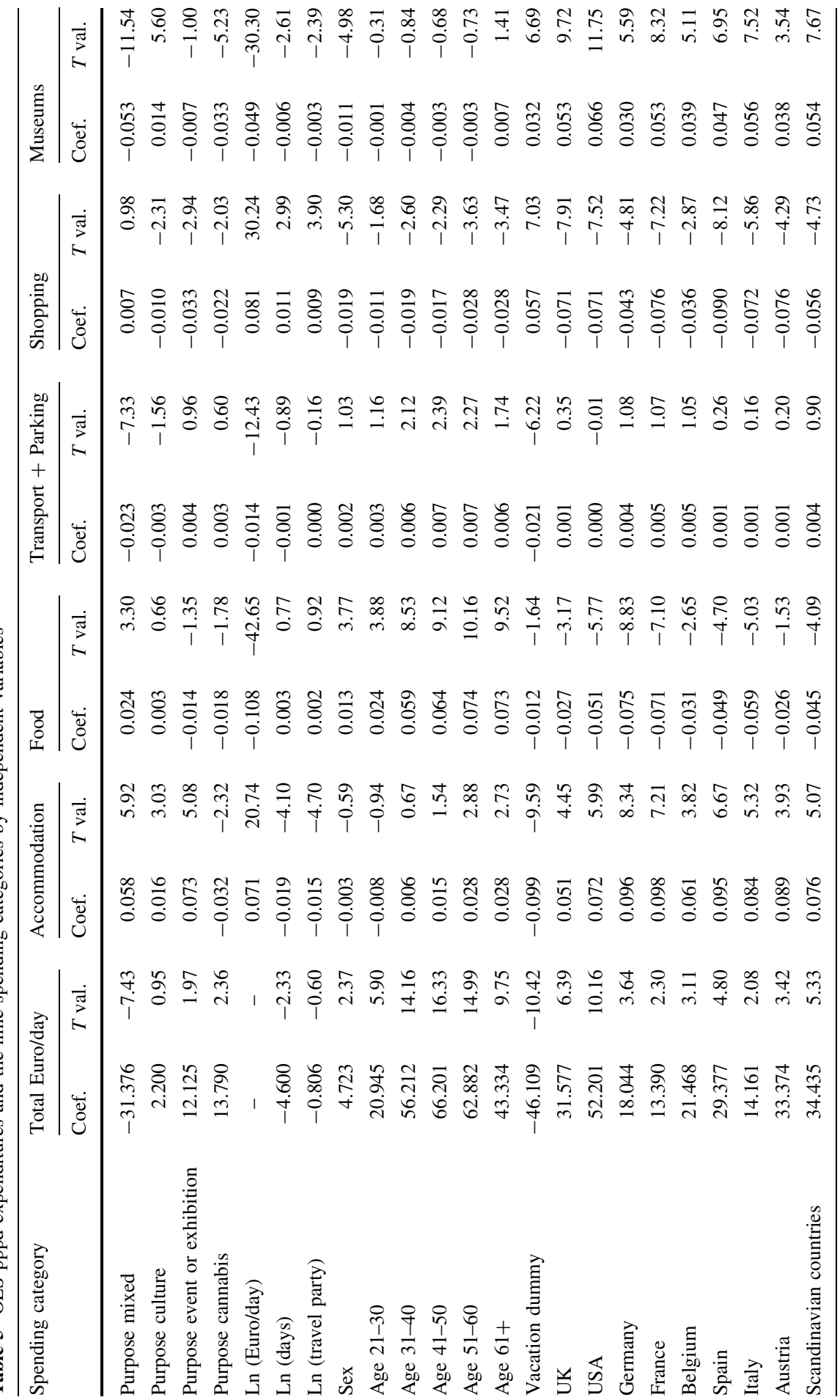




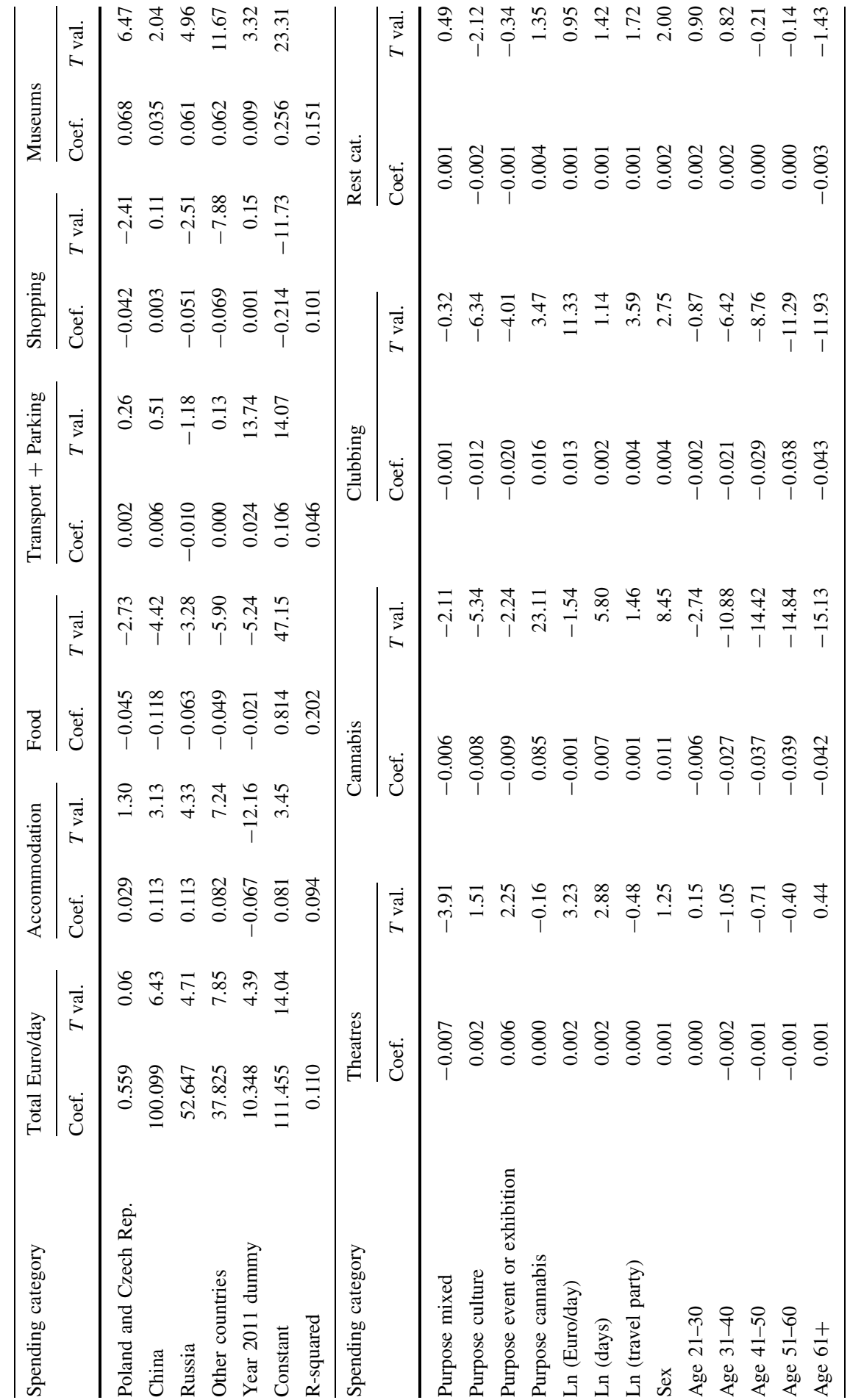




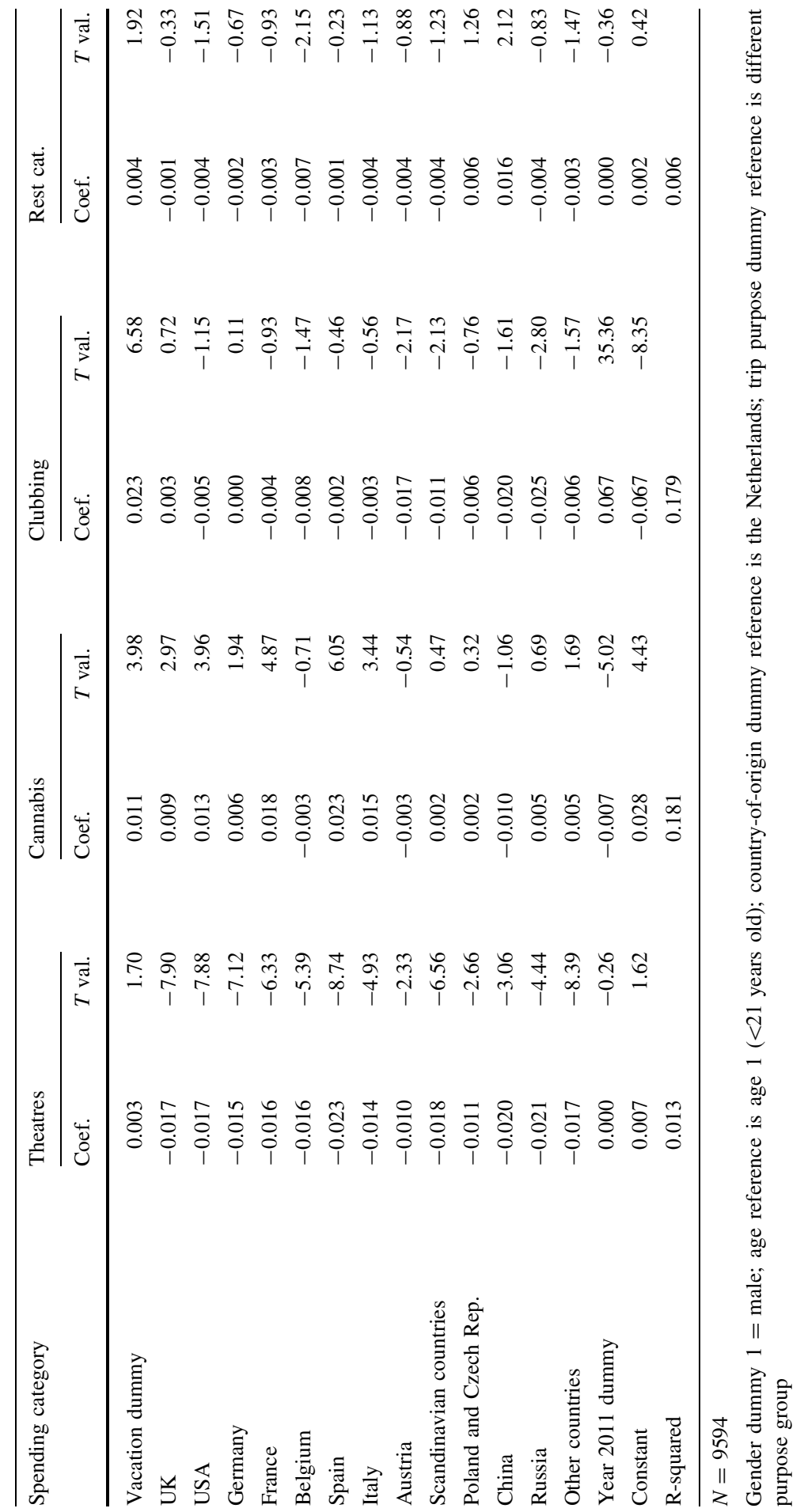


There are a number of other findings that warrant some discussion. Column 1 of Table 5 indicates that tourists visiting Amsterdam spend less per person per day $\left(\right.$ pppd $\left.^{13}\right)$, the more days they stay overnight. ${ }^{14}$ The size of the travel party does not have a significant effect on the total amount spent pppd. A similar result is reported by Wang et al. (2006), whereas Thrane and Farstad (2011) and Mok and Iverson (2000) find a negative effect.

Male respondents report to spend more than female respondents, but it is not entirely clear how to interpret this result when respondents do not travel on their own. For instance, most of the expenditure of a couple may be paid by the male, whereas consumption is mostly shared.

Tourists aged 41-50 spend the highest amount of money pppd, followed by those aged 51-60 and 31-40. The oldest and youngest tourists spend the smallest amounts pppd. This is in line with the findings of Thrane and Farstad (2011). The coefficient of the vacation dummy indicates that respondents who are on vacation spend significantly less pppd than respondents who are in Amsterdam for business reasons (the reference category). The difference between the two groups is large because businessmen/women stay in more expensive hotels and travel more often by taxi (AMSTERDAM MARKETING 2012).

The estimated coefficients for the country-of-origin dummies confirm that the respondents with the longest travel distance have the highest expenditures. Respondents from China spend the most money pppd, followed by Russians, while US respondents occupy the third place. Among the Europeans, Scandinavian respondents spend the most money pppd, followed by the Austrians and Brits. However, for the shorter travel distances, the relationship between travel distance and expenditures is less clear. It should be kept in mind that Dutch visitors are the reference category. Their daily expenditure is lower than that of all other categories.

The year dummy for 2011 is significantly positive and indicates substantially higher amounts spent pppd compared with 2006. Note that the expenditure figures have been adjusted for inflation using the cpi figures from the Statistics Netherlands. The financial crisis apparently did not have a negative impact on the expenditure of Amsterdam tourists. And estimated figures for the total number of tourists indicate that in 2011 there were substantially more tourists in 2011 compared with 2006 (Research and Statistics (O\&S) Amsterdam 2013).

\subsection{Budget shares}

The equations for the budget shares of the nine categories of spending confirm that there are important differences in the spending patterns of the tourists visiting Amsterdam. We find many significant coefficients and the difference in budget shares can be as large as $7 \%$ points (accommodation for those visiting an event or exhibition) of even $8 \%$ points (cannabis for those coming especially for that propose). There is only one significant coefficient for trip purpose for the budget

\footnotetext{
13 pppd = per person per day.

14 Our findings are consistent with those of Thrane and Farstad (2011) who find a significant positive effect of the natural $\log$ of length on the log of total personal tourism expenditures over all days.
} 
shares food, transport and parking, and the rest category. Visitors coming to Amsterdam with mixed purposes spend a larger share of their budget on accommodation and food and less on theatres and museums than the reference group. For those focusing on culture, the differences with the reference group are usually small in \% points, although sometimes highly statistically significant. Visitors of events or exhibitions differ most from the reference group in the budget share of accommodation. When cannabis is the main travel purpose, expenditure shares on all other categories except clubbing are negative or not statistically significant.

With respect to trip purposes, we see that respondents travelling to Amsterdam for an event or exhibition-controlling for other variables-allocate most of their daily budget to accommodation, followed by mixed purpose travellers, culture purpose travellers, other purposes, and finally respondents with the cannabis trip purpose. When we focus further on the other shares of spending categories in relation to trip purpose, we see that cannabis tourists allocate their budget only significantly more to buying cannabis and clubbing; the coefficients of the other categories are negative or insignificant. The respondents who come especially for culture allocate relatively more of their daily budget to museums, theatres and accommodation and significantly less to shopping, clubbing and cannabis. This difference in budget allocation shows that these groups are distinct in their spending behaviour and can be targeted differently by tourism marketing and offers.

The Engel curves that we estimate have the logarithm of total daily expenditure (the total spending pppd) as explanatory variable. This is the Working-Leser specification used in the almost ideal model of Deaton and Muellbauer (1980). Estimated coefficients show that a higher pppd budget implies that a larger share of the money is allocated to accommodation, shopping, theatres and clubbing and less to food (confirming Engel's law), transport and parking, and museums, whereas the share of expenditure on cannabis does not change. The categories with a positive coefficient are luxuries: their budget share increases with the size of daily expenditure. For instance, for accommodation a 50\% increase in daily expenditures from $€ 139$ (the average in our sample) to $€ 208.50$ will lead to an increase of: $\beta_{\mathrm{Ln}(\text { euro } / \text { day })} * \ln \left(\frac{208.5}{139}\right)=0.071 * \ln (1.5)=0.029$ percentage point of budget share. The example shows that the differences in budget shares that are related to travel purposes are large compared to those of the total travel budget.

The log of the number of days stayed in Amsterdam has a negative impact on the budget share for accommodation and a positive one on shopping, while its effect on other categories is more limited. The same remark holds for the size of the travel party.

For the male dummy, we find negative coefficients on shopping and museums and a positive one for cannabis. This is quite suggestive, although for this variable the same caveat holds as for total daily expenditure.

With a higher age, more is spent on accommodation, food and $\operatorname{transport}^{15}$ and less on shopping, cannabis and clubbing.

\footnotetext{
${ }^{15}$ For this category especially the difference between those in their twenties or older is relevant.
} 
The larger daily expenditure of foreigners is associated with higher budget shares for accommodation and museums and lower ones for food and shopping. It should be recalled that Dutch visitors are the reference.

The coefficients for the 2011 dummy show that the larger daily expenditure in that year was associated with lower budget shares for accommodation (possibly reflecting limited increases in hotel rates due to the crisis) and an equally higher budget share for clubbing.

\section{Discussion and conclusion}

The results presented above provide important information about the behaviour of tourists and shed light on the relationship between trip purposes and spending patterns. Most tourists who come to Amsterdam visit the city primarily for its rich cultural amenities. The attractions tourists visit are not limited to those fitting their main trip purposes. For example, all tourists who come to Amsterdam are likely to visit a museum. Tourists who come to Amsterdam for the cannabis will most probably do more than just visit a cannabis shop and use cannabis.

One, somewhat surprising finding is that the total expenditures per person per day for those with cannabis as their main travel purpose are the highest of all groups, when controlling for other characteristics, which suggests that quasi-legalized cannabis contributes more to the Amsterdam economy than was previously thought. Those coming to Amsterdam primarily for cannabis spend more of their daily budget on clubbing than the others, and they allocate significantly less of their daily budget to museum visits. Our results suggest that the Amsterdam cannabis culture implies a separate type of cultural tourism offer, besides the 'regular' cultural offerings associated with built heritage, museums and cultural events. Visiting a cannabis shop is often part of a trip to Amsterdam for those with other primary motives for coming to the city.

The results of the expenditure analysis further show the differences in expenditure patterns between the different types of tourists. The budget estimation results indicate that with a higher budget per person per day, a larger share of the budget is allocated to accommodation, shopping, theatres and clubbing and less to food, transport and parking, museums and cannabis. The largest effects are for shopping and accommodation. Thus, a relatively large part of the money from 'big spenders' flows to these categories. Concerning length of stay, the results show that the total daily budget decreases with an increase in the number of days tourists stay overnight. But the total trip budget is positively related to length of stay, meaning that the longer tourists stay, the more they spend in total, but less per day. Tourists who are on vacation spend significantly less per person per day than respondents who visit Amsterdam for business reasons. Business travellers spend significantly more on accommodation and transport and less on shopping, museums, cannabis and clubbing.

The estimated coefficients for the country-of-origin dummies confirm that the respondents with the longest travel distance have the highest expenditures. Of the different countries of origin, the Chinese, the Americans and the Russians spend the 
most money per person per day in Amsterdam. Table 5 shows that these tourists allocate their budget more than others to expensive accommodation and to museum visits. This is in line with the results reported earlier in this paper (in Sect. 4). Tourists from these countries are an interesting customer group for high-end hotels and the many museums in Amsterdam. Besides the cultural attractions in Amsterdam, the shops heavily rely on tourists for their turnover. The results indicate that the Dutch overnight tourists allocate more of their daily budget to shopping than tourists from other countries and probably remain an important or even the most important group for the shops in Amsterdam.

The year dummy provides insights into some shifts in spending behaviour of tourists to Amsterdam. The daily per person budget was higher in 2011 compared with 2006, and in the light of the global economic crisis, where a decline in budget was expected, this is an interesting result. We see that, in 2011, significantly more of the daily budget was allocated to transport and parking (which might be due to high increases in tariffs to clubbing) and to museum visits. The impacts of price differences between the 2 years are absorbed in the coefficients of the year dummy for the various categories. ${ }^{16}$ In 2011, less of the budget is allocated to cannabis, accommodation and food expenditures.

This study provides useful insights for destination marketers, with respect to the different groups of tourists and their expenditure behaviour and their frequently overlapping interests in Amsterdam's tourism offerings. The study helps to design specific marketing strategies for different target groups, in order to attract the preferred tourists.

Acknowledgements We would like to thank Hans Dominicus, Olivier Ponti and AMSTERDAM MARKETING for providing the data and the possibility to do research on site. We would also like to thank the members of the Department of Spatial Economics for helpful discussions. Ruben van Loon gratefully acknowledges NICIS, CLUE, Nieuwland, and VU University for their financial support. We are grateful to the editors and referees for useful remarks that helped to improve the paper. Any remaining errors or shortcomings are the sole responsibility of the authors.

Open Access This article is distributed under the terms of the Creative Commons Attribution 4.0 International License (http://creativecommons.org/licenses/by/4.0/), which permits unrestricted use, distribution, and reproduction in any medium, provided you give appropriate credit to the original author(s) and the source, provide a link to the Creative Commons license, and indicate if changes were made.

\section{Appendix}

\section{See Table 6.}

On the answer sheet:

Purpose Culture A respondent must have marked purposes indicated with an $\mathrm{X}$ and not marked the purposes indicated with a dash, and could also have marked purposes indicated with an $\mathrm{O}$

\footnotetext{
$\overline{16}$ We do not have systematic information on prices for accommodation.
} 
Table 6 Trip purposes

\begin{tabular}{llllll}
\hline $\begin{array}{l}\text { Activities mentioned on the } \\
\text { questionnaire }\end{array}$ & $\begin{array}{l}\text { Purpose } \\
\text { culture }\end{array}$ & $\begin{array}{l}\text { Purpose event } \\
\text { or exhibition }\end{array}$ & $\begin{array}{l}\text { Purpose } \\
\text { cannabis }\end{array}$ & $\begin{array}{l}\text { Mixed } \\
\text { purposes }\end{array}$ & $\begin{array}{l}\text { Other } \\
\text { purposes }\end{array}$ \\
\hline Historical culture, old city, canals & $\mathrm{X}$ & - & - & $\mathrm{X}$ & - \\
Rembrandt 400 activities & $\mathrm{O}$ & $\mathrm{O}$ & $\mathrm{O}$ & $\mathrm{O}$ & $\mathrm{O}$ \\
Special event or exhibition & - & $\mathrm{X}$ & - & $\mathrm{X}$ & - \\
Relaxed atmosphere and cosiness & $\mathrm{O}$ & $\mathrm{O}$ & $\mathrm{O}$ & $\mathrm{O}$ & $\mathrm{O}$ \\
Easy to travel to & $\mathrm{O}$ & $\mathrm{O}$ & $\mathrm{O}$ & $\mathrm{O}$ & $\mathrm{O}$ \\
Special travel offer & $\mathrm{O}$ & $\mathrm{O}$ & $\mathrm{O}$ & $\mathrm{O}$ & $\mathrm{O}$ \\
Cannabis & - & - & $\mathrm{X}$ & $\mathrm{X}$ & - \\
Reputation as capital of the Netherlands & $\mathrm{O}$ & $\mathrm{O}$ & $\mathrm{O}$ & $\mathrm{O}$ & $\mathrm{O}$ \\
Museums & $\mathrm{X}$ & - & - & $\mathrm{X}$ & - \\
Feel the Rhythm activities & $\mathrm{O}$ & $\mathrm{O}$ & $\mathrm{O}$ & $\mathrm{O}$ & $\mathrm{O}$ \\
Shopping & $\mathrm{O}$ & $\mathrm{O}$ & $\mathrm{O}$ & $\mathrm{O}$ & $\mathrm{O}$ \\
Close by & $\mathrm{O}$ & $\mathrm{O}$ & $\mathrm{O}$ & $\mathrm{O}$ & $\mathrm{O}$ \\
Part of a tour & $\mathrm{O}$ & $\mathrm{O}$ & $\mathrm{O}$ & $\mathrm{O}$ & $\mathrm{O}$ \\
Must have been there & $\mathrm{O}$ & $\mathrm{O}$ & $\mathrm{O}$ & $\mathrm{O}$ & $\mathrm{O}$ \\
Modern architecture and design & $\mathrm{O}$ & $\mathrm{O}$ & $\mathrm{O}$ & $\mathrm{O}$ & $\mathrm{O}$ \\
Nice experience last visit & $\mathrm{O}$ & $\mathrm{O}$ & $\mathrm{O}$ & $\mathrm{O}$ & $\mathrm{O}$ \\
To discover non-touristic Amsterdam & $\mathrm{O}$ & $\mathrm{O}$ & $\mathrm{O}$ & $\mathrm{O}$ & $\mathrm{O}$ \\
Other activities & $\mathrm{O}$ & $\mathrm{O}$ & $\mathrm{O}$ & $\mathrm{O}$ & $\mathrm{O}$ \\
\hline
\end{tabular}

Purpose Event or Exhibition

Purpose Cannabis

Mixed Purposes

Other purposes
A respondent must have marked purposes indicated with an $\mathrm{X}$ and not marked any of the purposes indicated with a dash, and could also have marked purposes indicated with an $\mathrm{O}$ A respondent must have marked purposes indicated with an $\mathrm{X}$ and not marked any of the purposes indicated with a dash, and could also have marked purposes indicated with an $\mathrm{O}$ A respondent could possibly have marked one or more of the purposes indicated with an $\mathrm{O}$, and at least two marked with an $\mathrm{X}$

A respondent could possibly have marked purposes indicated with an $\mathrm{O}$, but not marked any purposes indicated with a dash

\section{References}

Allegre, J., Cladera, M., \& Sard, M. (2011). Analysing the influence of tourist motivations on tourist expenditure at a sun-and-sand destination. Tourism Economics, 17, 813-832.

AMSTERDAM MARKETING (2012). 'Amsterdam Visitors Profile 2012', Amsterdam Tourism \& Convention Board.

Chung, K. Y., Oh, S. Y., Kim, S. S., \& Han, S. Y. (2004). Three representative market segmentation methodologies for hotel guest room customers. Tourism Management, 25, 429-441. 
Crouch, G. I. (1994). The study of international tourism demand: A survey of practice. Journal of Travel Research, 33(4), 41-55.

Crouch, G. I. (1995). A meta-analysis of tourism demand. Annals of Tourism Research, 22, 103-118.

Deaton, A., \& Muellbauer, J. (1980). Economics and consumer behaviour. Cambridge: Cambridge University Press.

Eymann, A., \& Ronning, G. (1997). Microeconometric models of tourists' destination choice. Regional Science and Urban Economics, 27, 735-761.

Fricker, S., Kopp, B., Tan, L., \& Tourangeau, R. (2015). A review of measurement error assessment in a U.S. household consumer expenditure survey. Journal of Survey Statistics and Methodology, 3, 67-88.

Gorman, W. M. (1980). A possible procedure for analysing quality differentials in the egg market. Review of Economic Studies, 47, 843-856.

Laesser, C., \& Crouch, G. I. (2006). Market segementation by reasons and influences to visit a destination: The case of international vistors to Australia. Tourism Analysis, 11, 241-249.

Lancaster, K. J. (1966). A new approach to consumer theory. Journal of Political Economy, 74, 132-157.

Lim, C. (1997). Review of international tourism demand models. Annals of Tourism, 24, 835-849.

Lim, C. (1999). A meta-analytic review of international tourism demand. Journal of Travel Research, 37, 273.

Lim, C. (2006). A survey of tourism demand modeling practice: Issues and implications. In L. Dwyer \& P. Forsyth (Eds.), International handbook on the economics of tourism (pp. 45-72). Cheltenham: Edward Elgar Publishing.

Mehmetoglu, M. (2007). Nature-based tourists: The relationship between their trip expenditures and activities. Journal of Sustainable Tourism, 15, 200-215.

Mok, C., \& Iverson, T. J. (2000). Expenditure-based segmentation: Taiwanese tourists to Guam. Tourism Management, 21(3), 299-305.

Nicolau, J. L., \& Mas, F. J. (2005). Heckit modelling of tourist expenditure: Evidence from Spain. International Journal of Service Industry Management, 16(3), 271-293.

Opperman, M. (1997). First-time and repeat visitors to New Zealand. Tourism Management, 18(3), $177-181$.

Oppermann, M. (1996). Visitation of tourism attractions and tourist expenditure patterns: repeat versus first-time visitors. Asia Pacific Journal of Tourism Research, 1(1), 61-68.

Pouta, E., Neuvonen, M., \& Sievänen, T. (2007). Determinants of nature trip expenditures in southern Finland-Implication for nature tourism development. Scandinavian Journal of Hospitality and Tourism., 6, 118-135.

Research and Statistics (O\&S) Amsterdam (2013).

Smith, S., \& Costello, C. (2009). Culinary tourism: Satisfaction with a culinary event utilizing importance-performance grid analysis. Journal of Vacation Marketing, 15, 99-110.

Spotts, D. M., \& Mahoney, E. M. (1991). Segmenting visitors to a destination region based on the volume of their expenditures. Journal of Travel Research, 29, 24-31.

Sung, H. H., Morrison, A. M., Hong, G.-S., \& O'Leary, J. T. (2001). The effects of household and trip characteristics on trip types: A consumer behavioural approach for segmenting the U.S. domestic leaure travel market. Journal of Hospitality and Tourism Research, 25, 46-68.

Thrane, C. (2002). Jazz festival visitors and their expenditures: Linking spending patterns to musical interest. Journal of Travel Research, 40, 281-286.

Thrane, C., \& Farstad, E. (2011). Domestic tourism expenditures: The non-linear effects of length of stay and travel party size. Tourism Management, 32, 46-52.

Van der Ark, L. A., \& Richards, G. (2006). Attractiveness of cultural activities in European cities: A latent class approach. Tourism Management, 27, 1408-1413.

Wang, Y., \& Davidson, M. C. G. (2010). A review of micro-analyses of tourist expenditure. Current Issues in Tourism, 13(6), 507-524.

Wang, Y., Rompf, P., Severt, D., \& Peerapatdit, N. (2006). Examining and identifying the determinants of travel expenditure patterns. International Journal of Tourism Research, 8(5), 333-346.

WTO (World Tourism Organization) (2005). City Tourism \& Culture: The European Experience. A Report produced for the Research Group of the European Travel Commission (ETC) and for the World Tourism Organization (WTO) by LAgroup \& Interarts. Brussels.

Wu, L., Zhang, J., \& Fujiwara, A. (2013). Tourism participation and expenditure behaviour analysis using a scobit based discrete-continuous choice model. Annals of Tourism Research, xx, 1-17. 